\title{
Food Safety Knowledge and Practices among Primary Food Preparers of under-5 children in an Urbanized Village of Delhi
}

\author{
Amrita Singh ${ }^{1}$, Kriti Gangwar ${ }^{2}$, Anita Verma $^{3}$, Surabhi Sethi ${ }^{4}$, Deepti Dabar ${ }^{5}$, Kundan Singh Rathore ${ }^{6}$
}

\begin{abstract}
Introduction: Food safety aims at ensuring that all food is as safe as possible. Children under 5 years of age carry $40 \%$ of the foodborne disease burden, with 125000 deaths every year. Aim and objectives: To assess the knowledge and practices regarding food safety in primary food preparers of under-5 children residing in Aliganj, field practice area of Vardhmann Mahavir Medical College and Safdarjung Hospital. Materials and methods: A community based cross sectional study was conducted amongPrimary food preparers for children under 5 years of age residing in Aliganj. Total of 110 food preparers were interviewd using a pre tested semistructured questionnaire was used for data collection. Results: All the primary food preparers in the study were housewives, majority $54.5 \%$ belonged to $20-25$ years, $87.3 \%$ women were literate, 95 (86.3\%) were homemaker and 71 (64.5\%) belonged lower middle class. Majority of women had correct knowledge and practice regarding separation of raw and cooked food, storing food in covered containers in fridge (57\%), 33\% had correct knowledge of storing food within 2 hrs. Most of women had correct knowledge regarding reheating of stored food before heating $83(75.5 \%)$ and practice 65 ( $73.5 \%)$ but $13(17.8 \%)$ practiced reheating food to correct temperature. Conclusion:There was found to be good practice and knowledge of separating raw and cooked food while a poor practice regarding storage, temperature of reheating stored food, reuse and reheating of cooking oil.
\end{abstract}

Keywords: food safety

\section{Introduction}

Food borne illnesses not only contribute to increased morbidity and mortality, they also affect socio-economic development. ${ }^{1}$ They consist of illnesses arising due to bacteria, viruses, protozoa, helminths, prions as well as diseases due to added chemicals and pesticides. They can cause diarrhoea and also lead to various other consequences such asrenal failure, liver failure, neurological disorders, arthritis etc. Chemicals, whether in the form of pesticides or as additives in food, can lead to non communicable diseases such as cancer, diseases affecting reproductive system as well as those affecting our immune system. ${ }^{2}$

WHO estimates about 32 disease conditions arising due to the various food borne hazards. Among these, diarrhoeal diseases, particularly due to Norovirus and Campylobacter, are the most common.Food safety aims at ensuring that all food is as safe as possible. An estimated 600 million almost 1 in 10 people in the world - fall ill after eating contaminated food and 420000 die every year, resulting in the loss of 33 million healthy life years (DALYs). Children under 5 years of age carry $40 \%$ of the food borne disease burden, with 125000 deaths every year.A very large proportion of food borne diseases occur due to improper handling of food at household/ commercial level. ${ }^{3}$ While people of all ages are susceptible to unsafe food, the effect is much more in children who tend to be affected by the vicious cycle of diarrhoea and malnutrition. Keeping the above in mind, the study aimed to assess the knowledge and practices regarding food safety in primary food preparers of under-5 children, in accordance with 'Five Keys to Safer Food' as formulated by WHO.

\section{Materials and Methods}

A community based cross sectional study was conducted among Primary food preparers for children under 5 years of age residing in Aliganj, field practice area of department of Community Medicine Vardhmann Mahavir Medical College and Safdarjung Hospital, Delhi. Data collection was done during August - September 2015. Since no study among primary food prepares of under five children was found, the 'sample size' was calculated using 'proportion formula for prevalence'; taking prevalence of $50 \%$ and absolute error as $10 \%$. The sample size came out to be 100 , to which a $10 \%$ non- response rate was added making a total sample size of 110. Aliganj has a total population of 6228 people, living in 1668 households (Baseline survey 2014 carried out by the Department) and 600 under five children. A child:household ratio of 3:1 was used, resulting in households visited for 110 children to be 330 . Hence, every 5 th house was visited, if the house was found locked or any child younger than 5 years old was not present in the household, the next house was visited. A pre-tested, semi-structured questionnaire was used for data collection. The primary food preparer was defined as the family member who prepares most of the meals of the family. Thedata collected was entered in MS excel and analyzed for mean, frequency and proportion.

\section{Results}

All the primary food preparers in the study were women in the age group 19-32 years. Majority of them (54.5\%) belonged to the age group of 20-25 years. Out of the total women interviewed, $96(87.3 \%)$ were literate, $95(86.3 \%)$ were homemaker and $71(64.5 \%)$ belonged lower middle class. (Table 1).

Table 1: Demographic profile of the study participants

\begin{tabular}{|c|c|c|}
\hline Sociodemographic characteristics & Number & $\%$ \\
\hline \multicolumn{3}{|c|}{ Age(years) } \\
\hline $20-25$ & 1 & 9 \\
\hline $25-30$ & 60 & 54.5 \\
\hline$\geq 30$ & 38 & 34.5 \\
\hline & 11 & 10 \\
\hline
\end{tabular}




\section{International Journal of Science and Research (IJSR) \\ ISSN (Online): 2319-7064}

Index Copernicus Value (2015): 78.96 | Impact Factor (2015): 6.391

\begin{tabular}{|c|c|c|}
\hline \multicolumn{3}{|c|}{ Educational Status } \\
\hline Illiterate & 14 & 12.7 \\
\hline Literate & 96 & 87.3 \\
\hline \multicolumn{2}{|c|}{ Occupation } \\
\hline Homemaker & 95 & 86.3 \\
\hline Housemaid & 8 & 7.3 \\
\hline Others & 7 & 6.3 \\
\hline Socio-economic status* & & \\
\hline Upper middle & 38 & 28.2 \\
\hline Lower middle & 71 & 64.5 \\
\hline Lower & 8 & 7.3 \\
\hline Total & $\mathbf{1 1 0}$ & $\mathbf{1 0 0}$ \\
\hline
\end{tabular}

*According to revised, Kuppuswamy scale (2014)

Half of the women interviewed, had correct knowledge and practice regarding separation of raw and cooked food $(50.9 \%)$. Most women $(\sim 57 \%)$ knew that food should be stored in covered containers in refrigerator.Thirty three percent had correct knowledge of storing food within $2 \mathrm{hrs}$. As far as 'reheating stored food before consumption' is concerned, $83(75.5 \%)$ had the adequate knowledge but only $65(73.5 \%)$ actually practised it with only 13 women $(17.8 \%)$ who practiced reheating food to correct temperature. Among 44 women who cooked non-vegetarian food, only $6(13.6 \%)$ knew correct cooking point of chicken. The women also had incorrect knowledge and practise of 'reusing cooking oil' with as many as 63 women (57.3\%) believing that cooking oil can be reused and 48 (43.6\%) always reusing it (Table 2).

Table 2: Distribution of study subjects according to Knowledge and practices assessed regarding food safety as per WHO five keys

\begin{tabular}{c|c|c|}
$\begin{array}{c}\text { Knowledge, attitude and practices assessed } \\
\text { regarding food safety }\end{array}$ & Number & $\%$ \\
\hline
\end{tabular}

A1) Knowledge does raw food needs to be stored separately from cooked food

\begin{tabular}{|l|l|l|}
\hline Yes & 56 & 50.9 \\
\hline No & 54 & 49.1 \\
\hline
\end{tabular}

A2) Fruits and vegetables separated from cooked food*

\begin{tabular}{|c|c|c|}
\hline Always & 75 & 68.2 \\
\hline Never & 23 & 20.9 \\
\hline Sometimes & 12 & 10.9 \\
\hline \multicolumn{3}{|c|}{ B1) Method of Storage of leftover food $(\mathrm{N}=40)^{*}$} \\
\hline -Open containers in fridge & 1 & 2.5 \\
\hline -Closed containers in fridge & 23 & 57.5 \\
\hline -Closed containers outside fridge & 16 & 40 \\
\hline
\end{tabular}

B2) Food to be stored, can be refrigerated within what time $(\mathrm{N}=24)$

\begin{tabular}{|l|l|l|}
\hline Immediately & 10 & 41.7
\end{tabular}

\begin{tabular}{|l|l|l}
\hline Within 2 hours & 8 & 33.3 \\
\hline After 2 hours & 6 & 25
\end{tabular}

After 2 hours

25

C) Reheating of stored cooked food

C1) Knowledge whether food should be reheated before consumption $(\mathrm{n}=110)$

\begin{tabular}{|l|l|l|}
\hline Yes should be reheated & 83 & 75.5 \\
\hline Should not be reheated & 27 & 24.5 \\
\hline
\end{tabular}

C2) Practice about reheating food before consumption $(\mathrm{n}=83)$

\begin{tabular}{|l|l|l|}
\hline Always & 61 & 73.5 \\
\hline Never & 10 & 12 \\
\hline Sometimes & 12 & 14.4 \\
\hline
\end{tabular}

C3) Practice regarding temperature to which food reheated before consumption ( $\mathrm{n}=73) \#$

Room temperature

\begin{tabular}{|l|l|}
3 & 4.1
\end{tabular}

\begin{tabular}{|c|c|c|}
\hline Warm enough to eat & 57 & 78.1 \\
\hline Till steaming hot & 13 & 17.8 \\
\hline \multicolumn{3}{|c|}{$\begin{array}{l}\text { D) Knowledge about cooking temperatures of non-veg food } \\
(\mathrm{N}=44)^{\wedge}\end{array}$} \\
\hline \multicolumn{3}{|c|}{ D1) Cooking of chicken $(n=44)$} \\
\hline Flesh is red & 18 & 40.9 \\
\hline Flesh is white & 6 & 13.6 \\
\hline Steaming if cut & 8 & 18.2 \\
\hline Others & 6 & 13.6 \\
\hline Don't know & 6 & 13.6 \\
\hline \multicolumn{3}{|l|}{ E)Reuse of cooking oil } \\
\hline \multicolumn{3}{|c|}{ E1) Knowledge regarding reuse of cooking oil $(\mathrm{N}=110)$} \\
\hline Can be reused & 63 & 57.3 \\
\hline Should not be reused & 38 & 34.5 \\
\hline Don't know & 9 & 8.2 \\
\hline \multicolumn{3}{|c|}{ E2) Practice regarding reuse of cooking oil $(\mathrm{N}=110)$} \\
\hline Always reuse & 48 & 43.6 \\
\hline Never reuse & 34 & 30.9 \\
\hline Sometimes & 28 & 25.5 \\
\hline
\end{tabular}

*only 40 out of 110 households used to have left over food, $\wedge 44$ individuals cooked non vegetarian food and \#73 are reheating out of 110

Majority of food handlers $72(65.5 \%)$ always used same type of water for cooking and drinking, $55(50 \%)$ drew water from glass without handle, majority $58(52.7 \%)$ consumed water without purification. Majority $92(82.7 \%)$ practiced washing vegetables in still water (Table 3 ).

Table 3: Other Practices regarding cooking/storage of food exercised by the respondents

\begin{tabular}{|l|c|c|}
\hline \multicolumn{1}{|c|}{ Other Practices } & Number & $\%$ \\
\hline 1. Usage of same type of water for cooking and drinking \\
\hline Always & 72 & 65.5 \\
\hline Never & 36 & 32.7 \\
\hline Sometimes & 2 & 1.8 \\
\hline
\end{tabular}

2. Distribution of study participants according to method of extraction of drinking water $(n=110)$

\begin{tabular}{|c|c|c|}
\hline Tap & 22 & 22 \\
\hline Glass without handle & 55 & 50 \\
\hline Mug with handle & 23 & 30 \\
\hline \multicolumn{3}{|l|}{ 3. Purification of water $(n=110)$} \\
\hline Consume after purification & 52 & 47.3 \\
\hline Consume without purification & 58 & 52.7 \\
\hline \multicolumn{3}{|c|}{ 4.Method used forPurification of water $(n=52)$} \\
\hline Boiling & 5 & 9.6 \\
\hline Aqua guard & 30 & 57.7 \\
\hline RO & 5 & 9.6 \\
\hline Candle filter & 12 & 23.1 \\
\hline \multicolumn{3}{|c|}{ 5. Practice of washing fruits and vegetables after buying } \\
\hline Wash with still water & 91 & 82.7 \\
\hline Wash with running water & 14 & 12.7 \\
\hline Don't wash & 5 & 4.6 \\
\hline
\end{tabular}

Majority of women cleaned hands 101 (91.8\%), keep nails trimmed $95(86.4 \%)$, tying and covering hair 96 (97.3\%), hand washing with soap $98(89.1 \%)$ before food preparation (Table 4). 


\section{International Journal of Science and Research (IJSR) \\ ISSN (Online): 2319-7064}

Index Copernicus Value (2015): 78.96 | Impact Factor (2015): 6.391

Table 4: Hygiene practices while cooking food $(\mathrm{n}=110)$

\begin{tabular}{|l|l|l|}
\hline $\begin{array}{c}\text { Hygiene practices while cooking food } \\
(n=110)\end{array}$ & Number & $\%$ \\
\hline 1. Cleaning hands before preparing food $(\mathbf{n = 1 1 0})$ \\
\hline Yes & 101 & 91.8 \\
\hline No & 9 & 8.2 \\
\hline
\end{tabular}

2. Keeping nails trimmed and clean while preparing $\operatorname{food}(n=110)$

\begin{tabular}{|c|l|l|}
\hline Yes & 95 & 86.4 \\
\hline No & 15 & 13.6 \\
\hline
\end{tabular}

3. Tying and covering hair while preparing food $(n=110)$

\begin{tabular}{|l|l|l|}
\hline Yes & 96 & 87.3 \\
\hline No & 14 & 12.7 \\
\hline \multicolumn{1}{|l|}{ 4. Removing ring and jewelry while preparing food $(\mathbf{n}=\mathbf{1 1 0})$} \\
\hline Yes & 55 & 50 \\
\hline No & 55 & 50 \\
\hline \multicolumn{2}{|l|}{ 5. Hand washing practices before food preparation } & $(\mathbf{n}=\mathbf{1 1 0})$ \\
\hline Yes & 106 & 96.4 \\
\hline No & 4 & 3.6 \\
\hline 6. Practice of hand washing & 98 \\
\hline Wash with soap & 11 & 89.1 \\
\hline With water & \multicolumn{2}{|l|}{} \\
\hline 7. Washing after using toilet & 108 & 98.2 \\
\hline Yes & 2 & 1.8 \\
\hline No &
\end{tabular}

\section{Discussion}

Majority of the study participants had both the knowledge and followed the practice of separating raw food from cooked food. All the participants who stored left over food had knowledge about reheating food before consumption and also followed it as a practice. However, they were not aware about the temperature up to which the food should be reheated and also the reason behind it. In their study conducted among women, Sarada Vadlaman et $\mathrm{al}^{2}$ had also found a gap between correct knowledge $(94.7 \%)$ and good practice $(30.7 \%)$. In their study, $32 \%$ women always separated raw and cooked food despite $94.7 \%$ having the knowledge of the same. However, in our study,even though only $50.9 \%$ women knew that food should be separated, as many as $68.2 \%$ practiced separation of food as a habit.A gap was also found in the number of participants having the knowledge regarding reheating stored food versus those actually practicing it. While $83(75.5 \%)$ women had the knowledge, $65(73.5 \%)$ actually reheated stored food. The study also revealed that some participants $(17.8 \%)$ were not aware of correct temperature to which food should be reheated. Percentage of participants always reheating stored, cooked food were only $16 \%$ in the study conducted by Sarada Vadlaman et al. ${ }^{4}$ In the present study majority of the mothers of under five children practiced washing fruits and vegetables after buying (95.4\%), similar findings were observed by Sudershan RV et al. that mothers of under five children practiced washing vegetables $(86.8 \%)$ and fruits (75.7\%) before consumption ${ }^{5}$ while Sarada Vadlaman et al found $48.7 \%$ always washed fruits and vegetables before eating. ${ }^{4}$ In our study $90 \%$ of the study participants use water and soap to wash their hands before food preparation. While Sudershan RV et al. observed that majority of mothers washed their hands before feeding the child $(86 \%)$ but more than $75 \%$ washed hands only with water. ${ }^{5}$ They observed that even after using toilet, only $50 \%$ used soap $^{3}$ while in our study $89.1 \%$ participants washed hands with soap. Sheethal
M P et al. in their study conducted among Aanganwadi workers, found all of them had practice of hand washing before cutting vegetables, handling food and after defecation. ${ }^{6}$ However, Sarada Vadlaman et al. observed 97.3\% had knowledge regarding importance of hand washing during handling of food but only $45.3 \%$ of them practiced it. $^{4}$

\section{Conclusion}

The participants exhibited a few good attributes and a few bad ones. Good knowledge and practice was found pertaining to separation of raw and cooked food but poor knowledge and practices were seen in the areas of storage and reheating of cooked food, especially regarding the temperature to which food should be reheated. Poor knowledge and practice regarding reuse of cooking oil was also observed in the study participants.

\section{Limitations and Strength}

There is a possibility of recall bias. The study can be used for conducting health talks and health education program and to assess KAP before and after application of such programs of risk communication. Discussing food safety with primary food preparers also make them conscious of their practices and also highlights the implications of basic hygiene of food preparer on the health of the entire family.

\section{References}

[1] WHO. Who estimates of the global burden of foodborne diseases. Available from: http://apps.who.int/iris/bitstream/10665/200046/1/WHO_ FOS_15.02_eng.pdf?ua=1 [Accessed on June 30 2017].

[2] WHO. Advancing food safety initiatives: strategic plan for food safety including foodborne zoonoses 2013-2022. Available from: http://apps.who.int/iris/bitstream/10665/101542/1/97892 41506281_eng.pdf?ua=1 [Accessed on June 30, 2017]

[3] WHO. Food Safety Factsheet. Available from http://who.int/mediacentre/factsheets/fs399/en/ last assessed on 26 june 2017.

[4] Sarada Vadlamani, B. Devi Madhavi, K. K. L. Prasad. Food Safety Knowledge, Attitude and Practices among Women in Field Practice Area of Urban Health Training Centre, Andhra Medical College, Visakhapatnam. Int J Evid Based Healthc. 2015;2(42): 73807388.

[5] Sudershan RV, Rao S, Polasa K. Women and food safety -some perspectives from India. Regional Health Forum 2009; 13: 11-13.

[6] Sheethal MP, Shashikantha SK. Knowledge, attitude and practice regarding food safety among the anganwadi workers in Mandya district. Int J Health Sci Res. 2015; 5(8):28-32. 